\title{
Laboreal
}

Volume 15 N$^{\circ} 2$ | 2019

Varia

\section{Os desafios do cuidado em situações-limite : as dramáticas da atividade no trabalho humanitário}

Los retos del cuidado en situaciones límite : las dramáticas de la actividad en el trabajo humanitario

Les défis des soins dans des situations limites : les dramatiques de l'activité dans le travail humanitaire

The challenges of care in extreme situations : the dramatics in the humanitarian work activity

\section{Luciana B. Cavanellas e Jussara Brito}

\section{OpenEdition}

\section{Journals}

Edição electrónica

URL: http://journals.openedition.org/laboreal/14966

DOI: $10.4000 /$ laboreal. 14966

ISSN: 1646-5237

\section{Editora}

Universidade do Porto

\section{Refêrencia eletrónica}

Luciana B. Cavanellas e Jussara Brito, "Os desafios do cuidado em situações-limite : as dramáticas da atividade no trabalho humanitário », Laboreal [Online], Volume 15 №2 | 2019, posto online no dia 01 dezembro 2019, consultado o 10 abril 2020. URL : http://journals.openedition.org/laboreal/14966 ; DOI : https://doi.org/10.4000/laboreal.14966

Este documento foi criado de forma automática no dia 10 abril 2020.

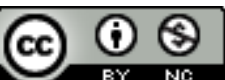

Laboreal está licenciado com uma Licença Creative Commons - Atribuição-NãoComercial 4.0 Internacional. 


\section{Os desafios do cuidado em} situações-limite : as dramáticas da
atividade no trabalho humanitário

Los retos del cuidado en situaciones límite : las dramáticas de la actividad en el trabajo humanitario

Les défis des soins dans des situations limites : les dramatiques de l'activité dans le travail humanitaire

The challenges of care in extreme situations : the dramatics in the humanitarian work activity

Luciana B. Cavanellas e Jussara Brito

\section{NOTA DO EDITOR}

Manuscrito recebido em dezembro 2017

Aceite após peritagem abril 2019

\section{Introdução}

O corpo vive porque se desintegra, sem se desintegrar demais... Só os sonhos são sempre o que são. (Fernando Pessoa)

Esse artigo é fruto de uma pesquisa de Doutorado em Saúde Pública sobre um campo onde o trabalho do cuidado em saúde atinge limites extremos, porque ocorre em situações de conflitos armados, epidemias, catástrofes naturais, fome etc. Nosso interesse de base está vinculado ao tema da saúde do trabalhador da saúde, revelando um contexto diferenciado e contornos muito particulares, relativos à atividade de trabalho inscrita no âmbito da medicina humanitária. 
2 O movimento humanitário contemporâneo tem seu início associado à criação da Cruz Vermelha (croix-rouge), por Henri Dunant, filantropo suíço, em 1864, após testemunhar a agonia de milhares de feridos no campo de batalha de Lombardie, em Solferino. Revoltado com o espetáculo de sofrimento que presenciou, Dunant tomou a iniciativa de providenciar socorro aos soldados, sem distinguir-lhes a procedência (Brauman, 2009).

3 Seu testemunho transformou-se no livro "Un souvenir de Solferino", publicado em 1862, onde, além de descrever as atrocidades da guerra, o autor propôs a criação de sociedades permanentes de socorro aos feridos e a adoção de regras para seu funcionamento (Brauman, 2009).

4 Segundo Rony Brauman, médico, epidemiologista e ex-presidente da ONG Médicos sem Fronteiras, o sucesso do livro de Dunant, em diversos países europeus, colaborou para o surgimento da Cruz Vermelha e da Convenção de Genebra, em 1864, inaugurando o chamado direito internacional humanitário, trazendo um novo significado ao termo e constituindo o fundamento do "espírito humanitário para além de qualquer divisão em nações, etnias ou religiões" (Brauman, p. 15, tradução livre).

5 Com o tempo, o movimento humanitário expandiu-se e deixou de contemplar somente feridos e exilados de guerra, estendendo-se a populações consideradas vulneráveis, cuja existência e dignidade estejam sob ameaça. Houve, então, uma proliferação de organizações e profissionais envolvidos na ajuda humanitária.

6 A não-indiferença ao outro e a seu sofrimento, base do movimento humanitário, tornou-se central na problematização das questões de responsabilidade e direito de interferência sobre a vida alheia.

7 Em 2003, Eric Stobbaerts, então Diretor de MSF Espanha, escreveu no prólogo do livro Humanitario, El dilema, sobre a perda do sentido original do "humanitário", falando com indignação sobre o uso que determinados governos ou multinacionais vêm fazendo do termo para engendrar campanhas, cujos objetivos distanciam-se barbaramente da proposta de salvar vidas e de respeito à dignidade humana (como citado em Brauman, 2003).

8 Nesse texto, ele também se refere às dificuldades operacionais e à capacidade de resposta das organizações humanitárias, diante de situações tão complexas, ressaltando que hoje as fronteiras, além de políticas, são também de ordem econômica, cultural e social (como citado em Brauman, 2003)

9 Oriundos da Cruz Vermelha, Bernard Kouchner e um grupo de médicos e jornalistas voluntários na guerra de Biafra (1967-1970), inconformados com fatos presenciados e silenciados diante de limites e entraves burocráticos e políticos, resolvem criar em 1971, na França, a Organização Médicos sem Fronteiras (MSF), com o compromisso de aliar socorro médico e testemunho, em favor das populações em risco.

Em "Les métiers de l'humanitaire et de la solidarité", ao abordar as diferenças e características das associações e organizações no âmbito do humanitário, Aubrée diz que com Médicos sem Fronteiras (MSF) surge uma "era de médicos franceses que partem para cuidar além das fronteiras e das separações ideológicas" denominando-os "os sem fronteiristas" (Aubrée, 2004, p. 13).

11 Apesar das diferenças filosóficas e dos modos e estratégias de intervenção, essas grandes estruturas de caráter médico humanitário atuam a partir do envio de profissionais ao campo (terreno), com o propósito comum de não se deixar limitar por 
"fronteiras internacionais, interesses estatais ou imperativos diplomático-estratégicos" (Ferreira, 2010, p. 29).

12 Em nossa pesquisa, elegemos "Médicos Sem Fronteiras", uma Organização NãoGovernamental Internacional de ajuda médico-humanitária, para nos aproximarmos e conhecermos o que e como se faz, quando se pretende salvar vidas e levar socorro médico a populações em risco, a partir da compreensão de que a atividade de trabalho é um objeto de pesquisa complexo. Como vivenciam o trabalho nas missões, como suportam o convívio com a fome e doenças negligenciadas, a exposição a guerras e conflitos armados, a insegurança diante de catástrofes naturais e epidemias; que recursos utilizam para lidar com o sofrimento inerente a tais situações e que consequências ou sequelas carregam, após deixarem as experiências do campo, constituíram perguntas fundamentais e fundantes desse estudo, cuja construção se baseou na perspectiva ergológica.

\section{Aporte teórico-metodológico}

13 Vários estudos acadêmicos voltados para o trabalho em saúde têm feito uso da perspectiva ergológica tanto do ponto de vista metodológico quanto teórico-conceitual (Brito, 2011). O paradigma ergológico abre-nos então um guarda-chuva de possibilidades, onde diversos pontos de vista e experiências são postos em conversações, visando uma maior interação e compreensão de determinada atividade de trabalho. Nesta pesquisa, de cunho qualitativo, a perspectiva ergológica permitiu uma análise em que também foram considerados os aportes da Psicodinâmica do Trabalho.

14 Ressaltamos também as contribuições da filosofia da vida de G. Canguilhem (referência teórica e epistemológica fundamental para a Ergologia), no que tange especificamente ao nosso olhar sobre a questão da saúde dos trabalhadores de MSF, que vivenciam situações de confronto com um meio imprevisível, abalado por contingências onde o caos muitas vezes se sobrepõe à ordem.

15 Nas palavras de Canguilhem, “a vida não é, portanto, para o ser vivo, uma dedução monótona, um movimento retilíneo ; ela é debate ou explicação com um meio em que há fugas, vazios, esquivamentos e resistências inesperadas" (Canguilhem, 2009, p. 149). Neste sentido, "a saúde é um guia regulador das possibilidades de reação" (Canguilhem, 2009).

16 A doença não pode ser entendida como mera oposição à saúde, visto que numa concepção dinâmica de busca de regulação, a doença também se manifesta como experiência que abre possibilidades ao organismo de instauração de novas respostas e novos padrões. "A doença não é uma variação da dimensão da saúde ; ela é uma nova dimensão da vida" (Canguilhem, 2009, p. 138).

17 Nisto consiste a concepção de saúde de Canguilhem, ao afirmar que :

Ser sadio significa não apenas ser normal em uma situação determinada, mas ser, também, normativo, nessa situação e em outras situações eventuais. 0 que define a saúde é a possibilidade de ultrapassar a norma que define o normal momentâneo, a possibilidade de tolerar infrações à norma habitual e de instituir novas normas em situações novas. (Canguilhem, 2009, p. 148). 


\subsection{A perspectiva ergológica}

18 A Ergologia reconhece o risco que a generalidade conceitual pode representar à singularidade, no afã de produzir modelos de comportamento, como dispositivos de análise e de gestão. É importante dispor de conceitos para pensar a ação humana, mas é preciso respeitar a história, que diferencia homens e mulheres que vivem e trabalham, de objetos a-históricos, foco das ciências naturais. Assumir tal postura, sem a esperada humildade é enfraquecer as dramáticas do uso de si, ignorando que homens e mulheres estão sempre renormatizando "os saberes, os procedimentos, os organogramas...E por meio disso, fragilizam os modelos e os conceitos elaborados sem eles" (Schwartz, 2003, p. 30)

Diante do reconhecimento da polarização entre os saberes formais, disciplinares e aqueles investidos e convocados na e pela atividade, a démarche ergológica busca desenvolver dispositivos de três polos por toda a parte onde é possível, voltando-se tanto ao campo das práticas sociais, como à elaboração dos saberes formais (Durrive \& Schwartz, 2008).

Nesta perspectiva, a Ergologia, segundo Pierre Trinquet (2010, p. 95), "representa um salto epistemológico no domínio das Ciências do Homem". Interessada na atividade humana e, mais precisamente, na atividade humana no trabalho, a orientação ergológica enxerga a necessidade de facilitar o encontro de diferentes saberes, disciplinas e abordagens. Prevê, então, um método que vise colocar em diálogo e debate : saberes eruditos e saberes da experiência (Trinquet, 2010), numa espécie de dupla confrontação : dos saberes entre si e dos saberes com as experiências da atividade (Durrive \& Schwartz, 2008).

21 Esses dois polos de saber são postos em confronto no interior do Dispositivo Dinâmico de Três Polos, não sem antes incluir um terceiro polo articulador, capaz de representar uma postura ética de respeito às diferenças, mantendo vigilância sobre a possibilidade do encontro e do diálogo entre os dois outros polos e visando a complementaridade, numa relação dialética.

22 Para Schwartz, trata-se de uma exigência ética, de respeito, mas também de uma exigência epistemológica, sem cuja postura "nos faltaria um espaço de compreensão do que torna possível a história, as instituições, o próprio trabalho" (Schwartz, 2007c, p. 268).

23 Neste sentido, entendemos que a perspectiva ergológica de Yves Schwartz em sua posição de "desconforto intelectual permanente" (Schwartz, 2007a, p. 31) e o arcabouço teórico construído em torno da ideia de atividade servem-nos como eixo conceitual e condutor da abordagem do trabalho nesta pesquisa, na medida em que enxerga seu caráter essencialmente criativo, dinâmico e singular.

24 A atividade de trabalho, nesta perspectiva, é atividade humana, em sua multiplicidade dramática, em oposição à inércia e à indiferença, "nunca pura execução ou alienação. Ela é sempre tentativa - mais ou menos individual, mais ou menos coletiva, [...] - de reinventar maneiras de fazer, maneiras de viver as contradições, os constrangimentos, os recursos do presente" (Schwartz, 2003, p. 25). Por isso, seu lugar de acontecimento é o do momento, da situação, de quem trabalha, inventa e transforma o já posto e existente em algo novo e original. 

dramáticas dos usos de si.

Neste confronto com o real, que nunca se apresenta conforme imaginado ou prescrito é preciso gerir os usos de si (Schwartz, 2007b). A atividade pressupõe usos de si por si e usos de si por outros, estabelecendo-se na dialética, no diálogo, na ambiguidade, nos encontros e desencontros entre essas instâncias que acabam por configurar as

O coletivo de trabalho, "os outros", o universo social atravessa toda e qualquer atividade, de modo visível e invisível, na presença e ausência, de colegas, chefes, clientes, pessoas, sociedade. A Ergologia cria o conceito de entidades coletivas relativamente pertinentes (ECRP) para abordar esse coletivo, as relações, trocas, escolhas e negociações relativas aos usos de si no trabalho.

Exige-se que cada um, além de aplicar regras, faça 'uso de si' (por/para outrem, dadas as normas antecedentes; por/para si, dadas as necessárias renormatizações, fazendo a gestão da (sua) vida, em uma tensão, uma 'dramática' relação consigo e com os outros (Athayde \& Brito, 2011, p. 263).

O drama das arbitragens nas situações de trabalho, entre os "usos de si por si" e "os usos de si pelos outros", entre o prescrito e o real, entre o sujeito e o mundo tem lugar no corpo. 0 corpo assume assim o viés da situação, como articulador de diferentes dimensões e propiciador de diálogos e debates.

Em tempos contemporâneos onde, uma vez "descoberta" a subjetividade é rapidamente convertida em recurso humano, matéria utilizável, controlável e até prescrita, Schwartz nos convoca a resistir às tentativas de objetivação do sujeito e para isso recorre ao corpo, como entidade irredutível, cujas experiências ultrapassam tentativas de tradução. "O 'corpo-si', árbitro no mais íntimo da atividade, não é um "sujeito" delimitado, definido, mas uma entidade enigmática que resiste às tentativas de ser objetivado" (Schwartz, 2007b, p. 198).

O autor propõe a expressão corpo-si (corps-soi) por reconhecer e desconfiar da noção de subjetividade como melhor forma de se referir a algo que nos é tão caro e intrínseco, mas, ao mesmo tempo, tão complexo e enigmático.

[...] Ora, falando do corpo e principalmente do corpo-si coloca-se o dedo sobre "alguma coisa" que nos ultrapassa a todos, na medida em que isso nos remete às profundezas do que somos - a essa "alguma coisa' que é, digamos novamente, biológica, mas atravessada pela nossa história. Ou seja, nós trabalhamos nosso corpo, nós o trabalhamos permanentemente pela nossa experiência de vida - e, portanto, por nossas paixões, por nossos desejos, por nossas experiências (Schwartz, 2007b, p. 199).

Athayde, ao discorrer sobre a saúde mental e o trabalho, nos diz, referindo-se à Ergologia, que "nesta perspectiva, toma-se o humano de 'corpo inteiro', como um 'corpo-si', um corpo-atividade-potência" (Athayde, 2011, p. 359).

Esta expressão - corpo-atividade-potência - criada na junção de três palavras, reforça a escolha pela Ergologia como ponto de partida, mas também caminho, na tentativa de compreendermos a atividade de trabalho dos profissionais de MSF.

Nas palavras de Schwartz: "A saúde começa com a tentativa de redesenhar parcialmente o meio em que se vive, em função de suas próprias normas, elaboradas por sua história" (Schwartz, 2011, p. 139). 

obra de seu principal autor, Cristophe Dejours. O corpo assume lugar privilegiado no conhecimento, na execução e na vivência da atividade de trabalho. Dejours nos fala de um corpo inteiro, sede da inteligência e da habilidade, guiada por uma intimidade estabelecida entre o corpo e os objetos de seu trabalho.

Essa inteligência, adquirida no exercício da atividade de trabalho, é denominada de inteligência prática, enraizada no corpo, fundamentalmente astuciosa e criativa e manifesta nas expressões, reações e realizações do sujeito, de maneira singular e enigmática.

40 A inteligência do corpo é própria de um engajamento; de quem vive e sofre as experiências, descobrindo defesas e alternativas para manter-se, equilibrando-se.

É sempre o corpo que é envolvido em primeiro lugar. Contrariamente ao que supõe o senso comum, o próprio trabalho intelectual não se reduz a uma pura cognição. Ao contrário, trabalhar passa, primeiro, pela experiência afetiva do sofrimento, do pático. Não existe sofrimento sem um corpo para experimentá-lo [...] A subjetividade só se experimenta na singularidade irredutível de uma encarnação, de um corpo particular e de uma corporeidade absolutamente única. (Dejours, 2004, p. 29). 
41 A psicodinâmica do trabalho de Dejours estabelece a relação entre sofrimento e prazer no trabalho, dando visibilidade ao engajamento subjetivo do trabalhador, sua mobilização, estratégias e possibilidades de criação e adoecimento no exercício de sua atividade.

42 Na visão de Ferreira (2010), a noção de sofrimento é central na obra de Dejours, implicada com as formas de constituição da organização do trabalho, onde a divisão das tarefas, os ritmos e modos operatórios prescritos e, sobretudo, a divisão dos homens representada pelas hierarquias, repartições de responsabilidade e sistemas de controle podem entrar em conflito com o funcionamento psíquico dos trabalhadores, emergindo um sofrimento patogênico. Esta ideia se contrapõe à de sofrimento criativo, que busca dar sentido ao trabalho.

43 A cooperação, neste contexto, ocupa lugar importante, por escapar a qualquer tentativa de previsibilidade e estabelecer-se a partir de relações de confiança baseadas na ética (Dejours, 2008a).

44 A questão do sentido do trabalho, explorada pela psicodinâmica do trabalho assume um ponto nevrálgico em nossa investigação, considerando ligar-se intrinsecamente à concepção de saúde que escolhemos como fundamento.

Dejours desmistifica a ideia de saúde mental como um estado de completo bem-estar e conforto, explicitando o papel da angústia como estimuladora de processos de transformação, onde "há fins, objetivos, desejos, esperanças" (Dejours, 1986, p. 9). Para esse autor, a saúde é quando é permitido ter esperança (Dejours, 1986).

\section{Estratégias adotadas} onde tivemos acesso a documentos publicados pela organização e conversamos com profissionais responsáveis pelo suporte psicossocial aos expatriados, assim como com alguns expatriados brasileiros, provisoriamente lotados no CO. Essas visitas e conversas foram fundamentais como primeira aproximação do campo de pesquisa, permitindo a coleta de informações iniciais e fomentando questões que mais tarde puderam ser retomadas nas entrevistas.

Os Diários de Bordo constituem um material importante de contato com as experiências dos trabalhadores de MSF em missão. São textos escritos por eles durante as missões, contando suas impressões no terreno, com redação livre, que passa por uma revisão do setor de comunicação do escritório Brasil, visando principalmente evitar algumas exposições que poderiam colocar sua segurança em risco. trabalhadores em missão, o que foi importante para a estruturação e condução das entrevistas.

51 - Participação em sessões de apresentação de filmes e visitas a exposições

52 Para divulgar seu trabalho internacionalmente, a Organização Médicos Sem Fronteiras realiza filmes e documentários, promovendo debates, em várias cidades e países. Com o 
mesmo intuito, organiza exposições, facilitando o acesso do grande público ao trabalho humanitário, também como forma de cativar mais doadores. no Coração da Cidade", montada em várias cidades brasileiras, que simulou um campo de refugiados, apresentando o trabalho realizado por MSF, envolvendo os participantes na tentativa de aproximá-los de uma realidade estrangeira. As observações feitas durante esses eventos trouxeram novos elementos para os diálogos que foram estabelecidos posteriormente. novembro de 2012 a janeiro de 2013, onde pudemos conversar com profissionais de Recursos Humanos (RH), responsáveis pelo processo seletivo dos expatriados brasileiros, conhecendo de perto as etapas da seleção, além de documentos de orientação aos selecionados para as missões.

Nesse período, contamos com a disponibilidade dos profissionais do escritório, destacando-se uma das psicólogas que nos ajudou a selecionar e contatar os candidatos às entrevistas. Baseados nessa primeira lista, elegemos aqueles a quem iríamos entrevistar, considerando o interesse da pesquisa, com caráter exploratório, em contemplar a maior diversidade possível quanto à formação, na área da saúde, e às suas experiências, isto é, os países/contextos onde já houvessem trabalhado. A faixa etária e o tempo de vinculação com a ONG também seguiram os mesmos princípios. Por fim, levamos em consideração a disponibilidade de profissionais, de ambos os sexos, que não estivessem em missão no período de entrevistas.

57 - Entrevistas

58 Foram entrevistados dez trabalhadores da ONG Médicos Sem Fronteiras, sendo dois médicos, duas médicas, um farmacêutico, uma farmacêutica, duas psicólogas, uma enfermeira e um enfermeiro, com idades entre 34 e 54 anos e tempo de trabalho variando de 1 a 10 anos no MSF, conforme quadro abaixo : 
Quadro : Caracterização dos trabalhadores entrevistados, segundo sexo, ano de nascimento, formação e tempo em MSF

\begin{tabular}{|c|c|c|c|c|}
\hline IDENTIFICAÇĀO & SEXo & ANO DE NASCIMENTO & FORMAÇÃO & TEMPO EM MSF \\
\hline E1 & $\mathrm{F}$ & 1976 & MÉDICA & DESDE 2007 \\
\hline E2 & M & 1971 & MÉDICO & DESDE 2005 \\
\hline E3 & M & 1978 & FARMACEUTICO & DESDE 2008 \\
\hline E4 & $\mathrm{F}$ & 1981 & FARMACÊUTICA & DESDE 2011 \\
\hline E5 & $\mathrm{F}$ & 1971 & PSICÓLOGA & DESDE 2010 \\
\hline E6 & M & 1976 & MÉDICO & DESDE 2012 \\
\hline E7 & $\mathrm{F}$ & 1973 & PSICÓLOGA & DESDE 2010 \\
\hline E8 & $\mathrm{F}$ & 1982 & ENFERMEIRA & DESDE 2011 \\
\hline E9 & $\mathrm{F}$ & 1962 & MÉDICA & DESDE 2012 \\
\hline E10 & M & 1963 & ENFERMEIRO & DESDE 2009 \\
\hline
\end{tabular}
Figueiredo, 2015, p. 44).

Para a definição do modo de condução das entrevistas encontramos em autores que vêm utilizando o pensamento de Mikhail Bakhtin, em suas pesquisas e estudos em Ciências Humanas, uma potente interlocução por também considerarem que "o saber teórico, instituído academicamente, precisa interagir com as percepções construídas no cotidiano das relações sociais, possibilitando uma permanente troca (...)" (Freitas, Souza \& Kramer, 2003, p.7). Também para Bakhtin, é na tensão entre os polos singularizante e universalizante que residem a riqueza e o desafio das Ciências Humanas (Amorim, 2003). Não há como fugir dessa tensão, mas é preciso admiti-la de início. "Somente somos iguais no plano teórico e abstrato ; no plano empírico, cada um de nós ocupa um lugar singular e único" (como citado em Amorim, 2003, p. 14).

Assim sendo, ao mesmo tempo em que os enunciados são únicos e não se repetem, do ponto de vista da historicidade, são dialógicos, "tecendo sentidos" no diálogo com outros enunciados (Pereira \& Rodrigues, 2010). Em consonância com esses autores, entendemos a importância das entrevistas como momento privilegiado de contato e produção de mundos, textos e sentidos, longe de considerá-las mero instrumento de coleta de informações ou opiniões a respeito de algo.

Concebidas como método, as entrevistas tornam-se pontes que propiciam ao entrevistado investir-se no diálogo, não como mero informante, mas como sujeito da análise, tomando para si "a tarefa de interpretar o trabalho" (Alvarez, França, \&

Seguindo essa visão, não há na entrevista uma verdade a ser desvelada que, correspondendo à realidade, responderia às perguntas da pesquisa, confirmando ou refutando hipóteses. 0 encontro entre entrevistador e entrevistado caracterizam a entrevista como "dispositivo enunciativo" (Rocha, Daher, \& Sant'Anna, 2004), autorizando práticas de linguagem que implicam uma configuração de coenunciadores, impulsionando sujeitos a produzirem textos. Defende-se através desse enfoque, a entrevista como opção política. 

diálogos com os profissionais, com foco em quatro grupos temáticos, definidos a partir de nossas questões iniciais de pesquisa e da aproximação prévia do campo. Assim, na condução dos diálogos buscamos abordar sequencialmente todos os grupos temáticos, abaixo explicitados :

\section{terceiro grupo temático apareceram intimamente relacionados, esses foram tratados conjuntamente. Além disso, com frequência, alguns assuntos eram recorrentes em diversos momentos das entrevistas. A dinamicidade na produção dos enunciados era viva e ativa, provocando idas e vindas nas conversações. \\ 4. Análise das entrevistas : descobrindo mundos e valores}

Como efeito do modo empregado na análise dos materiais produzidos ao longo da pesquisa, abordaremos três questões nos tópicos que compõem essa parte do artigo, a saber: a escolha e as expectativas em relação ao trabalho humanitário; desafios e situações críticas da atividade de MSF e recursos utilizados no seu enfrentamento; os impactos do trabalho humanitário na saúde do trabalhador

\subsection{Escolha e expectativas em relação ao trabalho humanitário}

\subsection{1. "Mas o meu sonho era Médicos Sem Fronteiras"}

Observamos que, ao serem indagados sobre as expectativas em relação ao trabalho humanitário, sete entrevistados deixaram transparecer em seus discursos a relação com um desejo, muitas vezes antigo e anterior ao momento em que se é exigida ou esperada a decisão por uma profissão. Há uma imagem, um projeto, um sonho de 
interferir e de "mudar o mundo", que geram disponibilidade e mobilização para lançarse em "qualquer lugar do mundo, qualquer condição". Há um desejo claro, uma escolha deliberada por esse tipo de trabalho e uma relação com o conteúdo significativo da tarefa (Dejours, 1992). Abaixo destacamos alguns desses discursos em diálogo entre si :

B :

"Mas na verdade, assim, o que me motivou a trabalhar com Médicos Sem Fronteiras era ir pro terreno. Sempre foi ir pra missão. E eu sempre tive um sonho de trabalhar na Somália. Uma vez eu tinha lido uma matéria, enfim, falando sobre mulheres mutiladas e como era a situação na Somália, aquela mutilação genital e tal... Então aquilo tinha me tocado muito."

$\mathrm{N}$ :

"[...]porque eu realmente, assim, realizei um sonho. [...] Eu demorei quatro anos para conseguir entrar na organização. Esse foi um processo...

[...]A profissão que eu escolhi em prol... Eu queria usar as minhas oito horas diárias pra fazer um trabalho em prol de uma população, enfim, um trabalho.

[...]E na carta de motivação estava lá: "Estou disponível para ir para qualquer lugar do mundo, qualquer condição."

E :

"...tinha uma cena[...] eu tinha uma cena na minha cabeça, minha, eu numa guia, no meio

fio, atendendo uma senhora na Índia, não sei, eu coloquei isso na minha cabeça e me via mesmo, era uma cena minha."

No âmbito do trabalho em Médicos sem Fronteiras, fala-se em "motivação humanitária", como algo fundamental à realização do trabalho e que distingue este trabalhador de outros, mesmo na área da saúde.

Importante ressaltar que a equipe de $\mathrm{RH}$, além de fornecer todas as informações necessárias ao entendimento de cada missão, também faz questão de enfatizar que este não é um trabalho como os outros. "Não é uma seleção para um emprego. É uma opção de vida, onde todos, sem exceção, são transformados".

Lançar-se ao desconhecido, levar ajuda a quem precisa em contextos radicalmente diferenciados daqueles em que se vive, vencer limites, superar barreiras, arriscar-se por um trabalho que pressupõe exposição a situações inéditas, querer colocar-se a serviço do outro além das fronteiras experimentadas até então. Ser estrangeiro e ter a possibilidade de mergulhar em outros mundos e culturas pelo viés da ajuda humanitária parece constituir um valor especial a quem escolhe tornar-se membro de MSF.

\subsection{2. "Eu já cresci com uma bagagem muito de que fazer pelo outro é fazer por mim também"}

Muitos relatos referem-se a valores pessoais possivelmente ancorados em valores universais, não dimensionáveis, que não se mensuram em quantidades e que se referem 
ao bem-viver em comum (Schwartz, 2007c). Destacamos dois desses relatos, embora tenhamos identificado sete discursos nessa direção :

B :

“[...]0 trabalho voluntário, esse trabalho mais humano sempre foi muito comum na minha família, então, digamos, não sou pioneira disso. De maneira nenhuma, assim. As pessoas da minha familia, assim, minha vó, ela é de origem alemã e ela na época do pós-guerra abriu uma escola em Friburgo pra receber as pessoas que vinham da guerra, ensinar português, alemão, ia dar vacina nas crianças. Enfim, eu cresci um pouco com essa história, essas histórias. E minha mãe... bom, como boa brasileira, sou totalmente mestiça : minha mãe vem do Amazonas, que também era uma familia super... Enfim, o pai dela, era... Trabalhava no Itamaraty na parte de fronteira, então ajudava muito os índios, também. Então eu já cresci com uma bagagem muito de que fazer pelo outro é fazer por mim também".

A :

“... eu queria trabalhar em África e eu queria, porque eu achava, assim, tem muita necessidade de... de atendimento de saúde e não tem tanto profissional. Essa era a minha ideia assim de quem não conhecia muito, mas..."

Ao escolher o trabalho humanitário, e isso é perceptível nas entrevistas, essas pessoas o fazem baseadas em ideias que identificam como humanitárias, que se preocupam com interesses humanos, que veem a humanidade como um coletivo

Valores como altruísmo, compaixão e solidariedade, ainda que não nomeados desta forma pelos entrevistados, parecem naturalmente associados a um trabalho onde há o despojamento de um modo de vida confortável e pretensamente seguro, em prol de pessoas e populações que vivem em contextos fundamentalmente diferenciados, desprovidos de condições básicas, vítimas de guerras, conflitos, fome e doenças.

No momento em que se escolhe ser um "Médico sem Fronteiras", essa escolha baseia-se no desejo de ajudar a pessoas doentes e necessitadas, de fazer algo de realmente útil ao outro, de diminuir o sofrimento de quem padece. "Impossível dar realidade a estes valores sem lhes atribuir uma dimensão, sem lhes alocar recursos..." (Schwartz, 2007b, p. 251). Mas esse polo dos chamados valores dimensionados não são os que movem os profissionais que optam pelo trabalho humanitário, pelo menos não na origem de sua escolha.

\subsection{3. "A seriedade da organização pra mim 'tava ligada a esses princípios, e foi só em Médicos Sem Fronteiras que eu encontrei".}

79 Alguns relatos, como os que se seguem (selecionados dos seis que registramos), deixam claros a admiração e a identificação com os valores de MSF, além da confiança na organização, o que parece não só colaborar, mas muitas vezes fundamentar a decisão de se tornar um "médico sem fronteiras".

$\mathrm{J}$ : 
"O que me chamou atenção em MSF foi a valorização que eles davam para cada profissional, assim. Era bem diferente de qualquer outro emprego que eu conversasse com amigos meus. A gente é bastante ouvido. Eles valorizam bastante o profissional."

S :

"a seriedade da organização pra mim 'tava ligada a esses princípios, e foi só em Médicos Sem Fronteiras que eu encontrei."

80 Ao projetar e escolher uma determinada atividade de trabalho deliberadamente, decide-se por um meio de realização de potencialidades identificadas, que encontram ressonância na imagem e nas ideias que se tem a respeito daquele trabalho. Assim sendo, escolher um trabalho diz respeito à construção e confirmação da identidade do indivíduo, considerando-se saudável procurar, através do trabalho, a construção da identidade no campo social. Isso está relacionado diretamente à mobilização subjetiva $\mathrm{e}$ a uma espécie de direito à contribuição, que remete ao plano ético (Dejours, 2008b).

Para Dejours (2008c), apoiando-se em Ricoeur, "a identidade é uma promessa”, jamais definitivamente conquistada e a atividade, apesar de não produzir identidade, "é o que proporciona a oportunidade de um encontro entre a identidade e o real" (Dejours, 2008c, p. 261). Nesse sentido, o trabalho adquire caráter central na "construção da identidade, na realização de si mesmo e na saúde mental” (Dejours, 2008b, p. 140).

\subsection{4. "Eu andei caminhos longos pra atingir um objetivo"}

Sete entrevistados discorreram amplamente sobre o longo caminho percorrido até se tornarem trabalhadores de MSF, porém fizemos um recorte de dois depoimentos, visando fornecer alguns elementos para essa discussão :

E :

“[...]. Então a minha ideia foi "tudo bem, vamos tentando, eu sou persistente[...]fiquei sete anos trabalhando em Saúde Mental e mandando currículo, eles já sabiam o meu nome de cor..."

C :

"Eu fui pra primeira missão na Amazônia com esse, com essa ONG, era uma missão que ia durar três meses, e eu acabei ficando um ano nessa organização. Aí voltei pra, pro sul e no mês seguinte fui chamado por uma outra organização pra uma missão de dois anos, né? [...] fui emendando uma missão na outra.

[...] Fiz francês, fiz os quatro anos de francês, depois fiz inglês, três anos de curso, mas assim, sem pensar em sair do Brasil, sem pensar em, não sei, fui fazendo...

[...] É, foi um caminho assim, uma coisa meio tortuosa, meio longa, eu andei caminhos longos pra atingir um objetivo que eu não pensava ainda em atingir."

O processo de escolha de uma atividade de trabalho também é uma experiência singular, ancorada em histórias de vida, valores e anseios, movido pela necessidade, obrigação e/ou desejo (Revuz, 2007). Muitas vezes, o trabalho é considerado somente 
objeto de necessidade, como se fosse preciso "morrer em relação ao desejo" (Revuz, 2007, p. 230). Abandonar os sonhos, "deixar no vestiário todos os seus desejos, todo o seu imaginário" (Durrive, 2007, p. 230) e comprometer-se com a realidade.

Esse modo de selecionar pode ser um fator gerador de sofrimento posterior, quando se considera impossível conciliar os diferentes aspectos do trabalho: o trabalho como necessidade, sustento e como realização de desejo ; abrindo-se mão de parte importante na sustentação de uma atividade. "Na medida em que se reúna os dois é que se torna possível sobreviver no trabalho" (Revuz, 2007, p. 230).

A autora sugere que o trabalho é um objeto íntimo, comparando-o às escolhas amorosas, às vezes difíceis de explicar. Nesse sentido, já na preferência, o trabalho se revela enigmático, às vezes pouco provável ou incompreensível. É o enigma da atividade que já se apresenta na definição por esta ou aquela profissão, este ou aquele trabalho. Aquilo que faz alguém se direcionar às mais diversas frentes e encarar o que ainda não se pode imaginar, na intenção ou necessidade de realizar algo estritamente pessoal e, ao mesmo tempo, definitivamente político através de sua atuação no mundo.

O que constatamos aqui é que os trabalhadores de saúde que optam por trabalhar em Médicos sem Fronteiras são movidos por um desejo claro e consciente de participar ativamente na produção da sociedade, na criação do mundo mais do que na adaptação a ele. E pretendem fazer isso através do seu trabalho.

\subsection{Desafios e situações críticas da atividade de MSF e recursos utilizados no seu enfrentamento}

\subsection{1. "Um risco que vale a pena"}

87 A proximidade com contextos mais violentos e inseguros, traz à tona o contato com o extremo na sua acepção mais contundente, que é o limite entre a vida e a morte, tornando para alguns a possibilidade da morte uma realidade concreta.

Apesar do medo explicitado por um entrevistado e da tristeza gerada pela morte de pessoas conhecidas, parece haver algo que talvez possamos ousar nomear de uma prédisposição ao enfrentamento de situações adversas. Os entrevistados mostraram-se cientes dos riscos inerentes àquelas missões e dispuseram-se a lidar com eles, apesar da periculosidade e gravidade a que estavam expostos. A atitude de desapego numa situação extrema em que é preciso deixar tudo para trás convive com a necessidade de criar laços e referências afetivas na criação de um meio vivível (Schwartz, 2007b), um ambiente de trabalho que durante um tempo também será o seu lar.

B :

"É um trabalho. Essas pessoas aqui precisam de alguém pra fazer esse trabalho. Por acaso sou eu, né ? Eu tive a sorte de estar aqui, poder aprender com elas e poder viver isso".

A reflexão de Nouroudine (2004) a respeito dos riscos das atividades humanas, inspirada em Canguilhem, contribui com a análise dessa questão. $O$ autor traz uma visão mais positiva e criativa do risco e mesmo das infrações às normas de segurança, como modo de viver a atividade e mesmo de manter-se saudável no trabalho. Sem negar a importância das regras estabelecidas visando a segurança dos trabalhadores nas mais diversas profissões e situações de trabalho, o que o autor pretende é chamar a 
atenção para “o risco como ocasião de expressão da criatividade nas atividades humanas" (Nouroudine, 2004, p. 38).

No caso de Médicos sem Fronteiras e do trabalho em situações extremas, essa discussão parece adquirir outros contornos, se considerarmos os riscos inerentes a determinadas missões, como constituintes mesmo do trabalho, sem os quais talvez essa vertente do trabalho humanitário inexistisse. Tanto é assim que os trabalhadores de MSF têm a liberdade de escolher se aceitam ou não trabalhar em missões que envolvam riscos maiores. E uma vez que concordem, recebem todas as instruções necessárias à minimização dos mesmos ; regras da organização visando proteger os profissionais que aceitaram expor-se em nome da realização de um trabalho. A maneira como cada um irá proceder na situação diz respeito a modos próprios de agir e tem profunda conexão com a subjetividade e singularidade humanas.

\begin{abstract}
Se o correr risco pelos sujeitos individuais e coletivos produz-se no âmago da experiência, então cada uma de suas características imprime o risco com sua marca. [...] podemos considerá-lo negativamente como podemos vê-lo positivamente. Consequentemente, só podemos atingir sua significação situando-a na experiência dos protagonistas no contexto multidimensional das atividades realizadas. (Nouroudine, 2004, p. 52)
\end{abstract}

91 Nos depoimentos colhidos, é possível perceber a relação estabelecida com os riscos já assumidos para a realização da atividade. Mas cada um busca encontrar formas de lidar com as tensões, emoções e medos, tratando por vezes situações-limite como acidentais, talvez "subestimando" sua gravidade, encarando-as como parte do trabalho, cujo objetivo maior, de ajuda, se torna capaz de relativizar o caráter extremo de tais circunstâncias. Considerar a morte como parte da vida e uma possibilidade sem hora ou lugar pré-determinados, além da missão de "levar ajuda às pessoas que mais precisam sem discriminação de raça, religião ou convicções políticas" constituem valores comuns aos trabalhadores de MSF.

\title{
4.2.2. "Muita gente tem jeito melhor de lidar, muita gente tem pior".
} perspectivas, refere-se à complexidade da gestão do trabalho.

E :

“[...]do sequestro. (...) E aí tudo muito tenso, na hora fechou as atividades, parou tudo, ninguém sai, ninguém sai até segunda ordem, e aí tem, 'tá, eu não saio, mas e os pacientes ?'...[riso leve]... 'eu não saio mas eu tenho um grupo'..."

Apesar de reconhecer os riscos a que estava exposta se permanecesse no local, uma das entrevistadas demonstrou não ter lidado bem com a interrupção abrupta de seu trabalho, além da separação imediata dos colegas e dos pacientes. Algo a que vinha se dedicando com muito envolvimento e para o qual havia se preparado teve que ser abortado, sem aviso prévio. Além disso, o sequestro de duas trabalhadoras de MSF envolvia pessoas de sua ligação afetiva, o que também tornava sua condição especial neste caso. O tratamento dispensado pela Organização não lhe pareceu satisfatório, apesar de reconhecer algumas iniciativas. Eis uma situação onde as dramáticas da atividade se tornam explícitas, mobilizando tentativas e exigindo posicionamentos, 
escolhas para lidar com algo que é da ordem do imprevisto ; ou seja, que acontece na experiência real do trabalho e para o qual não se sabe o quanto preparado está, até que o momento aconteça de fato.

A gestão, como verdadeiro problema humano, advém por toda parte onde há variabilidade, história, onde é necessário dar conta de algo sem poder recorrer a procedimentos estereotipados. Toda gestão supõe escolhas, arbitragens, uma hierarquização de atos e de objetivos, portanto de valores em nome dos quais essas decisões se elaboram. (Schwartz, 2004, p. 23)

Gerir o trabalho implica gerir-se no trabalho, enfrentando limitações, dificuldades, descobrindo recursos e surpreendendo-se com superações, mas também com impossibilidades.

Se concordamos com a perspectiva ergológica que considera que o trabalho é sempre uso de si, gerir o trabalho é gerir os diferentes usos de si, por si e pelos outros, confrontando universos de macro com micro gestão, interesses externos e normas organizacionais com possibilidades e escolhas pessoais. Segundo Schwartz, essa negociação é sempre problemática, "sempre lugar de uma dramática" (Schwartz, 2004, p. 25).

No caso de MSF e dos trabalhadores da Saúde, em geral, essa gestão adquire características peculiares. "Podemos mesmo dizer que eles levam ao extremo as dramáticas" (Schwartz, 2005, p. 8). Há choque de valores e confrontos com valores não dimensionáveis na atividade de profissionais que se deparam com verdadeiros "dramas" alheios, enquanto tentam gerir os seus próprios.

É toda a grandeza e a dificuldade deste "trabalhar, gerir" dos profissionais de saúde : um encontro particularmente crítico de dramática de uso de si (...) que não pode ser facilmente codificado, procedimentarizado. (Schwartz, 2005, p. 8)

Uma das entrevistadas chama a atenção, em seu relato, para a questão das regras institucionais e do "controle". Sua abordagem nos remete ao conceito de normas antecedentes, com a relevância e complexidade que lhes são características.

C :

“...é, eles veem muito, assim, em uma missão eles veem um projeto, eles traçam, delineiam, é, um projeto, e você tem que seguir aquilo à risca, mesmo que um desvio à esquerda e um desvio à direita podem ser necessários pra melhoria mais à frente desse projeto, não, você tem que seguir pelo meio. É, então um pouco assim, eu, eu passei por isso no Paquistão, é, no Paquistão eles, momento assim de dece..., decepcionante pra mim do Paquistão..."

Parece-nos claro, em seu discurso, que a rigidez das regras era proporcional à insegurança do local dessa missão, o que provavelmente fez com que a Organização criasse uma série de protocolos para garantir o maior cuidado e proteção de seus profissionais, como é de praxe no âmbito do trabalho humanitário, pelo menos no que se refere a MSF. Mesmo com todas as medidas visando garantir ao máximo a segurança e preservação dos expatriados, houve um bombardeio num hospital próximo, o que afetou diretamente a rotina dos trabalhadores e da entrevistada em questão. Tal 
acontecimento vem reforçar a ideia da imprevisibilidade e infidelidade do meio (Canguilhem, 2009).

Interessante notar, na fala de outro entrevistado, a ênfase dada à necessidade dos protocolos como forma de facilitar o trabalho para quem permanece no terreno, quando há troca de médicos e profissionais:"[...] Num projeto onde você tem essa rotatividade, a única forma de você manter esse controle é você seguir protocolo, né ?"

\subsection{3. "O ser humano, quanto mais complexo o mundo no qual ele vive...mais complexo torna-se o relacionamento dele para com os outros"}

As relações profissionais estabelecidas nas missões são foco de uma série de depoimentos (todos os entrevistados se manifestaram em relação a isso), que ressaltam tanto a oportunidade de conviver com pessoas de culturas, hábitos e valores diversos, como também as crises e dificuldades resultantes dessa convivência no trabalho.

\section{S :}

"Eu acho que assim, além do trabalho, a segunda grande paixão é exatamente o staff nacional. Eu acho, que eu tenho uma, não vou dizer naturalmente porque eu sou uma psicóloga, mas eu tenho uma facilidade, um desejo, uma sensibilidade muito grande para outras culturas...

[...] Se você me vir depois de um mês de missão você vai achar que eu 'tô há um ano lá, porque tem uma conexão muito boa. E olha que o [...] nacional do Sudão do Sul não é nada, qualquer um vai te dizer isso, não é nada fácil, eles são muito, independente de quem você seja, eles são muito resistentes, muito difíceis. Mas, é clichê dizer isso, né ? E talvez até old fashion, mas eu amo, então eu passo por cima daquilo, é como se eu não estivesse vendo, né ? O meu sorriso é de verdade, sabe ?"

Como sugere Pezé, se o trabalho pode ser um operador potente na construção da saúde, ampliando a subjetividade, as possibilidades do corpo e da sensibilidade, existe também uma dimensão de sofrimento relativa aos conflitos intrapsíquicos e intrasubjetivos, visto que "trabalhar é se trabalhar" e também "trabalhar em conjunto" (Pezé, 2009, p. 16).

Para que o trabalho aconteça, não basta antecipar as diretrizes e coordenar funções e tarefas de cada um no grupo. As escolhas que cada um faz de si, os diferentes usos e modos de ser e agir pessoais, somados às inúmeras combinações possíveis entre pessoas, movidas por ideias, afetos e valores reforçam o caráter imprescritível da atividade. No trabalho humanitário, há que se destacar ainda os efeitos causados pelo encontro de culturas, as mais diversas, que se veem obrigadas a conviver dia e noite, sem descanso, durante as missões, principalmente nas que exigem maior restrição de movimentação, devido à insegurança local. É uma prova de fogo, que traz à tona os recursos individuais no confronto com o coletivo. "Renormatizar é também escolher com quem trocar piscadas de olhos, o que compartilhar, com quem, que patrimônio construir - ou destruir - ao longo dos dias" (Schwartz, 2011, p. 140).

o coletivo não está dado previamente. "Ele é indefinidamente variável no tempo, no espaço, infinitamente mais instável do que as interações previstas pelos protocolos, pelos organogramas" (Schwartz, 2011, p. 139). 
O agir coletivo, o coletivo em movimento na realidade do trabalho, suas iniciativas e combinações não são prescritíveis, como não são as relações de confiança e cooperação. Para Dejours (2008a), a dimensão da cooperação no trabalho diz respeito à contribuição dos agentes e às relações intersubjetivas, escapando aos limites da procedimentalização.

ara que a cooperação aconteça, é preciso antes que se estabeleçam relações de confiança entre os trabalhadores e estas referem-se ao compartilhamento das regras de ofício (Pezé, 2009) e baseiam-se mais em condições éticas do que propriamente afetivas (Dejours, 2008a). "Não tem 'você me ajuda'. A pessoa chega : 'Pô, tá carregando essa caixa. Eu carrego outra.' "

Ao criar o conceito de entidades coletivas relativamente pertinentes, a Ergologia procura tratar da dimensão do "viver junto" que acontece no trabalho, onde os protagonistas são convocados a engendrar um modo de gerir as situações, lidando com todos os "outros" que de modo instável e variável compõem o coletivo de trabalho. Fazer parte desse coletivo significa criar e recriar normas, fazer usos de si por outros, por si e para outros, rever e retrabalhar valores, construir e reconstruir incessantemente um meio onde seja possível viver e trabalhar.

\subsection{4. "Você se adapta, é im-pres-sio ...só vivendo pra saber, é impressionante".}

E :

"Não tinha estrutura nenhuma, só terra, a mesma comida o dia int..., todos os dias, né ? Morar com cento e vinte, cento e oitenta pessoas, chegou a cento e oitenta..."

Apesar de saberem da provisoriedade dessas experiências, algumas missões podem levar meses e é preciso se adaptar ao tipo de vida local, que pode variar absurdamente. Mesmo diante de um estranhamento inicial, ao se depararem com um contexto tão precário, os relatos de diversos entrevistados refletem uma capacidade adaptativa importante, que os permitiu manterem-se no terreno, diferentemente de outros trabalhadores mencionados.

108 O medo, os riscos e o desgaste são admitidos e denunciam as dramáticas da atividade. A falta de condições básicas de moradia e higiene, a exposição a guerras e a fenômenos naturais pouco comuns tornam mais exposta também a vulnerabilidade dos trabalhadores, afetando diretamente sua integridade física e trazendo o foco para o corpo. Quando isso acontece, fugas e disfarces tornam-se insuficientes para esconder as limitações concretas impostas pela realidade, onde o sofrimento físico é a própria impossibilidade de escapar do instante da existência (Lévinas, 1988). É a falta de refúgio, convite ao enfrentamento.

109 Para Dejours, "é sempre o corpo que é envolvido em primeiro lugar" (Dejours, 2004, p. 29), inteiro, encarnação da subjetividade, afetado pela experiência do trabalho e pelo sofrimento que ela acarreta.

110 Existe uma intimidade, uma relação com a matéria do trabalho que só é experimentada no corpo e a partir dele, e que o convoca a transformar-se a si próprio diante da resistência do real (Pezé, 2009). 


\subsection{5. "Ai meu Deus do Céu, não vou poder salvar o mundo"}

111 Chegamos aqui ao que nos parece um dos pontos cruciais, àquilo que toca a essência do trabalho humanitário, conforme vivido por essas pessoas : o contato com o sofrimento extremo de outra pessoa e as possibilidades e limitações do cuidado.

112 Vale ressaltar que essa percepção só é possível graças ao encontro de diálogos presentes nas entrevistas, que nos remetem à visão bakhtiniana de que a experiência verbal individual evolui na interação contínua com os enunciados do outro. Dessa forma, "os enunciados não são indiferentes uns aos outros, nem são auto-suficientes ; conhecem-se uns aos outros, refletem-se mutuamente. São precisamente esses reflexos recíprocos que lhes determinam o caráter." (Bakhtin, 1997, p. 316-317).

113 Todas as dificuldades e obstáculos relatados anteriormente referem-se, de certa forma, ao que é preciso atravessar para se aproximar de um outro desconhecido e distante, conhecer suas necessidades e oferecer-lhe ajuda. Esses trabalhadores deixam suas casas, rotinas, famílias e relações e lançam-se rumo ao que lhes é completamente estrangeiro para tocar no sofrimento do outro e "salvá-lo" da falta, da dor e daquilo que o mantém em condições que desafiam sua humanidade. A extrema pobreza, o abandono, a ausência completa de cuidados de saúde e de recursos, as perdas brutais em consequência de guerras, violência e conflitos intermináveis, a falta de liberdade, a impossibilidade de se viver em paz atraem e confrontam cuidadores imbuídos pelo espírito humanitário.

O sofrimento desses trabalhadores provocado pelo contato próximo com o sofrimento alheio, em situações de atuação limitada, nos parece colocá-los diante de alguns dos maiores desafios. Para Dejours (2008d), todo trabalho implica um confronto com o real que gera sofrimento. $\mathrm{O}$ real resiste às prescrições, conhecimentos, expectativas e convoca o trabalhador a se deslocar, defender, expressar, criar para transformar o sofrimento e "conquistar" o prazer no trabalho. O sofrimento tende a se manter quando, esgotados os recursos pessoais, o trabalhador se vê diante de obstáculos insuperáveis (Pezé, 2009). O que os faz conseguir preservar a mobilização espontânea para o trabalho, a despeito de toda a resistência, mudanças, dificuldades e decepções aponta para o foco das investigações da psicodinâmica do trabalho, em sua curiosidade pela normalidade enigmática do trabalhador.

Um dos eixos fundamentais de resposta a essa pergunta, segundo esta abordagem, passa pela dinâmica da contribuição/retribuição. Esse reconhecimento que pode ser manifestado tanto por superiores hierárquicos ou subordinados na organização do trabalho, como por colegas e pares, também pode advir dos clientes ou da própria comunidade e pode ter um sentido não só de constatação da contribuição individual, como de gratidão (Dejours, 2008).

116 Essa confirmação também acontece quando a atividade de trabalho é reconhecida coletivamente pela sua importância e contribuição à sociedade, como é o caso de MSF. Há um reconhecimento tácito. A relevância desse trabalho é praticamente inquestionável. E ainda que não houvesse o devido reconhecimento institucional, haveria o efeito imediato de gratidão de quem recebe ajuda e cuidados, fonte primordial de prazer para quem trabalha na assistência, no contato direto com os pacientes. Quando não há mediação que interrompa o fluxo do trabalho e o cuidado pode atingir diretamente quem precisa, o sentido do trabalho permanece vivo e ativo. "São essas coisas que eu acho que me fazem uma pessoa muito melhor". 


\subsection{Os impactos do trabalho humanitário na saúde do trabalhador}

\subsection{1. "Existe um desgaste, né ? Isso não tem como negar".}

117 Todos os entrevistados tinham muito o que dizer sobre os modos como sua saúde foi afetada durante as missões. Mas para introduzir esse tema destacamos apenas alguns trechos de entrevistas :

\section{M :}

"Mesmo que você pegue um projeto simples, um projeto que não puxe muito, não adianta. Você não tá relaxado. Você tá lá, é vinte e quatro horas, mesmo que você não esteja trabalhando vinte e quatro horas."

"Se você tem Médicos Sem Fronteiras uma vez, você vai pegar malária e tá tudo bem".

E :

...me impactou muito. Eu voltei da missão, por exemplo, em Dadaab destruída fisicamente mesmo, é, fiquei com anemia...

C :

Então nesse, nesse um mês que eu fiquei nessa atividade intensa eu acabei tendo essa hérnia inguinal...

118 A intensificação do trabalho refere-se não só ao número de horas trabalhadas diariamente ou à falta de separação entre vida pessoal e profissional em missão, mas também ao esforço maior colocado, muitas vezes sob o sacrifício do corpo, para aguentar uma bagagem ou ajudar a diminuir o sofrimento de um paciente. A maneira como cada um vive o trabalho, se coloca a serviço de sua atividade, respeitando e desrespeitando determinados limites refere-se à gestão dos usos de si, experienciada e refletida no corpo-si.

Mesmo a reação a uma ocorrência mais frequente em missões, como a diarreia ou a malária, pode vir a se tornar algo crítico, exigindo uma evacuação médica, como pode ser tratado como algo banal, que faz parte do trabalho e não merece destaque : "eu tive uma malariazinha, mas nada sério".

Se no físico, o desgaste causado pelo trabalho é detectado de maneira mais direta, sob forma de marcas, lesões, cirurgias, doenças conhecidas e tratáveis, como a malária para a qual existe inclusive a profilaxia, os efeitos psicológicos advindos do trabalho humanitário são menos objetiváveis e percebidos de forma mais sutil. Podem aparecer mais tardiamente, com menos obviedade, às vezes com pequenas alterações de humor (B), como algo difícil de definir (E) ou facilmente detectável nos outros, quando isso se mostra de forma contundente (C). Mas não pretendemos considerar tais aspectos separadamente, distintos em psico e soma, por tratarmos aqui do organismo como um todo em sua relação com o meio. Entendemos que tais fronteiras não são facilmente determináveis e adotamos a ideia de corpo-si para corroborar com a visão de unidade corpo-sujeito. As palavras dos entrevistados nos ajudam a confirmar essa tese : 


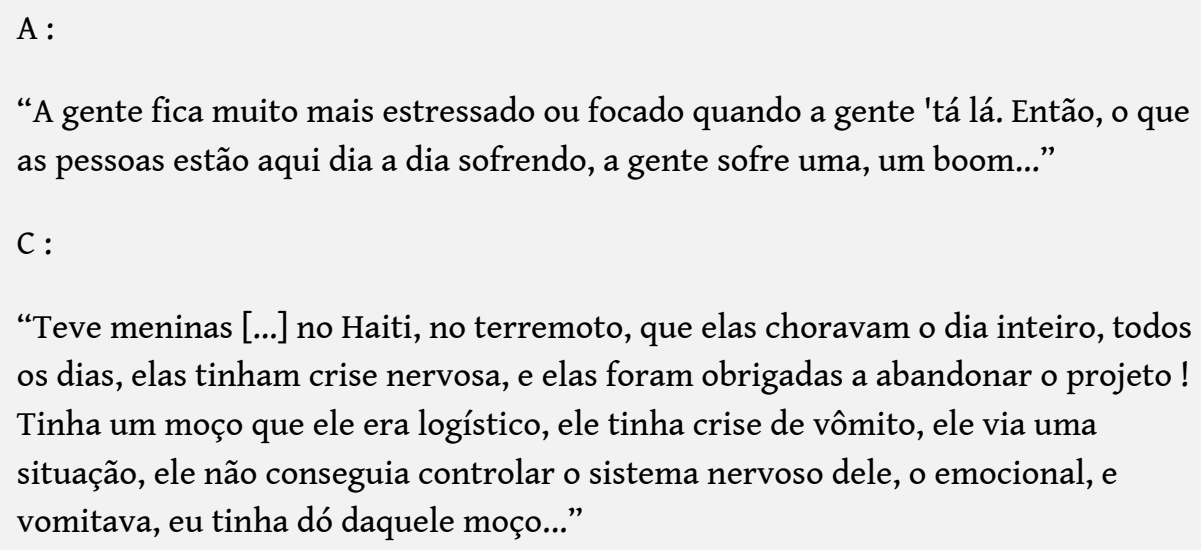

"Cada um procura no trabalho o equilíbrio aceitável entre uso de si requisitado e consentido" (Schwartz, 2007b, p. 200). O quanto cada trabalhador entende que pode entregar de si à atividade, sem que sua saúde sofra abalos graves e, na eventualidade de acidentes ou imprevistos, o modo como se cria possibilidades e novas normas diz respeito à característica mediadora do corpo-si (Schwartz \& Echternacht, 2009).

Em confronto com os espaços, tempos, limites e potencialidades da produção, no contato entre corpo e meio, "face a lacunas, a um 'vazio de normas', é preciso, acima de tudo, operar uma inventividade criadora, renormatizando" (Athayde \& Brito, 2011, p. 263). Para isso enfrenta os debates, as dramáticas dos usos de si e a não estandardização das situações a serem geridas.

Segundo Schwartz, saúde é poder encontrar um equilíbrio entre as normas individuais, as do coletivo relativamente pertinente e as do coletivo social (Schwartz, 2007b). Nesse sentido, as diferenças culturais também oferecem desafios importantes aos trabalhadores em missão, exigindo uma reconfiguração de seus hábitos, normas e valores, nem sempre possível.

\subsection{2. "O que que faz eu aguentar, eu não sei”}

O conjunto de relatos de nossos entrevistados (que não serão reproduzidos aqui devido à sua extensão) indica que, mesmo afetados em sua saúde pelas experiências de trabalho no terreno, independente do sexo, idade, tempo de trabalho em MSF, missões mais ou menos longas, mais ou menos arriscadas, eles têm um desejo de permanecer na atividade humanitária, expondo-se a novos contextos e riscos.

As vivências de situações extremas compartilhadas pelos trabalhadores de MSF entrevistados por nós são tratadas pelos próprios como caldeirão de acontecimentos e eventos críticos, com os quais cada um tem que lidar a partir de seus recursos, história, valores, em uma atividade atravessada por dramáticas de escolhas e de usos de si diante do ineditismo do presente.

Por outro lado, a organização procura prover toda a assistência necessária em relação a adoecimentos ou afastamentos de missão por questões relativas à saúde, conforme confirmam os relatos de nossos entrevistados, mas sempre há questões difíceis de prever.

De toda forma, mesmo aqueles, que reconhecem o desgaste sofrido no e pelo trabalho, não parecem carregar uma imagem de adoecimento associada aos eventos vividos, 
preservando a nosso ver uma ideia do trabalho como processo de construção de si mesmo e operador de saúde (Duraffourg, 2008), transformando o sofrimento em criatividade e beneficiando o fortalecimento de sua identidade (Dejours, Abdoucheli, Jayet, Dejours, \& Abdoucheli, 2010).

Nesse momento, à medida em que nos aproximamos mais e mais da atividade, confirmamos a relevância de um dispositivo como o DD3P, que pode explicitar lacunas e diferenças entre o patrimônio estocado dos conceitos e ideias a respeito de algo, e o patrimônio vivo da experiência relatada pelos trabalhadores :

C :

"[...]Os benefícios não são consolidados em ganhos materiais. Creio que se traduzem em propostas pessoais, o que me leva a fazer uma missão e se isso me traz o retorno esperado dentro de meu pensamento filosófico ou de minha construção de caráter. Dom e dádiva".

\section{Considerações finais}

No trabalho humanitário, profissionais se deslocam de seus países, deixando suas casas, para prestar ajuda a povos distantes e desconhecidos, sendo alvo de admiração, gratidão e reconhecimento. Ainda que as diferenças culturais configurem barreiras significativas, muitas vezes são considerados heróis e contam com uma valorização social, das pessoas de modo geral.

130 Ao final da pesquisa, verificamos tratar-se de um trabalho inspirado pela ideologia de um mundo melhor, baseando-se de fato em valores como altruísmo e preocupação com o sofrimento e necessidades do outro, sem fazer disso um motivo de heroísmo. Isso não significa que não haja conflitos em relação aos seus princípios e à preservação dos valores humanitários.

131 Parece haver, no entanto, para quem permanece vivendo desse trabalho, imerso em realidades críticas por longos períodos, um desgaste físico, mental e emocional grande que levanta questões acerca do tempo de possibilidade de engajamento e da continuidade do vínculo com a atividade. Não há dados estatísticos que comprovem tal suposição, mas Brauman (2003, p. 111) afirma que essa disponibilidade requerida tende a diminuir na maioria das pessoas. "A reserva de indignação e de compaixão necessárias para que a ação conserve todo o seu vigor e não se degrade em automatismos, não são inesgotáveis".

No entanto, na maioria dos relatos, são conflitos relativos à esfera da gestão, que engloba protocolos, procedimentos, decisões administrativas e, logicamente, modos diversos de pensar e agir humanos, que impactam mais diretamente na atividade de prestação de cuidados. Na visão do gestor de RH de MSF, os maiores problemas com os trabalhadores expatriados, que interferem na preservação ou não do trabalho são oriundos de conflitos de valores. Os valores presentes no trabalho precisam estar em coerência com os valores pessoais para que a atividade conserve seu sentido.

Ainda assim, há preocupação com os rumos da carreira do expatriado que pode passar alguns anos trabalhando em missões, mas que sentirá, com o tempo, a necessidade de diminuir seu ritmo e encontrar uma outra forma de poder colaborar. 
134 Alguns trabalhadores sofrem a "pressão" pela possibilidade de tentarem, em dado momento, voltar a uma "vida normal", constituir família e possuir um emprego. A vida humanitária traz repercussões contundentes para quem a escolhe, dificultando a formação de determinados vínculos e modelos reforçados socialmente.

135 É compreensível a dificuldade e mesmo a impossibilidade de saber como cada um reagirá em missão, visto tratar-se de modos singulares dos usos de si diante de um meio infiel, onde a capacidade normativa do corpo-si é convocada em situação.

Entretanto, podemos afirmar que deixar seu país e sua vida, romper barreiras e hábitos e ter sua liberdade cerceada nos parece um desafio emblemático a quem busca um trabalho sem-fronteiras. As normas antecedentes e a necessidade de checá-las, corrigi-las e reinventá-las na atividade configura-se como exercício de superação e ultrapassamento de fronteiras, que pode conferir sentidos paralelos ao trabalho. Porém, em todos os casos, o aspecto relacional, a parceria, a colaboração, a cooperação entre pessoas, colegas de trabalho nas circunstâncias, mostrou-se fundamental à realização do trabalho, traduzida na fala de um dos entrevistados: "quando o time é bom, a missão é boa".

\section{BIBLIOGRAFIA}

Alvarez, D., França, M. B., \& Figueiredo, M. (2015). Exercício Analítico sobre o Método : Aspectos Linguageiros na Atividade Dialógica com Trabalhadores de Exploração e Produção no Setor Petrolífero. Laboreal, 9(1), 39-52. doi :10.15667/laborealxi0115da

Amorim, M. (2003). A contribuição de Mikhail Bakhtin : a tripla articulação ética, estética e epistemológica. In M. T. A. Freitas, S. Jobim e Souza, \& S. Kramer (Orgs.), Ciências humanas e pesquisa : leituras de Mikhail Bakhtin (pp. 11-25). São Paulo : Cortez.

Athayde, M. (2011). Saúde, mental e trabalho : questões para discussão no campo da saúde do trabalhador. In C. M. Gomez, J. M. H. Machado, \& P. G. L. Pena (Orgs.), Saúde do trabalhador na sociedade brasileira contemporânea (pp. 345-366). Rio de Janeiro : Editora Fiocruz.

Athayde, M., \& Brito, J. (2011). Ergologia e clínica do trabalho. In P. F. Bendassolli, \& L. A. Soboll (Org.). Clínicas do trabalho (pp. 258-281). São Paulo : Atlas.

Aubrée, C. (2004). Les métiers de l'humanitaire et de la solidarité. Paris : L'Etudiant.

Bakhtin, M. (1997). A Estética da criação verbal. São Paulo : Martins Fontes.

Brauman, R. (2003). Humanitario el dilema. Barcelona : Icaria.

Brauman, R. (2009). La Médecine humanitaire. Paris : Puf.

Brito, J. (2011). A Ergologia como perspectiva de análise : a saúde do trabalhador e o trabalho em saúde. In C. M. Gomez, J. M. H. Machado, \& P. G. L. Pena (Orgs.), Saúde do trabalhador na sociedade brasileira contemporânea (pp. 479-494). Rio de Janeiro : Editora Fiocruz.

Canguilhem, G. (2009). o normal e o patológico (6a ed.). Rio de Janeiro : Forense Universitária. 
Canguilhem, G. (2012). 0 conhecimento da vida. Rio de Janeiro : Forense Universitária.

Dejours, C. (1986). Por um novo conceito de saúde. Revista Brasileira de Saúde Ocupacional, 14(54), 7-1.

Dejours, C. (1992). A loucura do trabalho : estudo de psicopatologia do trabalho. São Paulo : Cortez.

Dejours, C. (2004). Subjetividade, trabalho e ação. Revista Produção, 14(3), 27-34.

Dejours, C. (2008a). Addendum Da Psicopatologia à Psicodinâmica do Trabalho. In C. Dejours, S. Lancman, \& L. I. Sznelwar (Orgs.), Christophe Dejours : da psicopatologia à psicodinâmica do trabalho (pp. 49-106). Rio de Janeiro : Ed. Fiocruz; Brasília : Ed. Paralelo 15.

Dejours, C. (2008b). O Trabalho como Enigma In C. Dejours, S. Lancman, \& L. I. Sznelwar (Org.), Christophe Dejours : da psicopatologia à psicodinâmica do trabalho (pp. 129-141). Rio de Janeiro : Ed. Fiocruz; Brasília : Ed. Paralelo 15.

Dejours, C. (2008c). Análise Psicodinâmica das Situações de Trabalho e Sociologia da Linguagem In C. Dejours, S. Lancman, \& L. I. Sznelwar (Org.), Christophe Dejours : da psicopatologia à psicodinâmica do trabalho (pp. 245-289). Rio de Janeiro : Ed. Fiocruz ; Brasília : Ed. Paralelo 15.

Dejours, C. (2008d). Entre Sofrimento e Reapropriação. In C. Dejours, S. Lancman, \& L. I. Sznelwar (Org.), Christophe Dejours : da psicopatologia à psicodinâmica do trabalho (pp. 351-364). Rio de Janeiro : Ed. Fiocruz ; Brasília : Ed. Paralelo 15.

Dejours, C., Abdoucheli, E., Jayet, C., Dejours, C., \& Abdoucheli, C. J. (2010). Psicodinâmica do trabalho : contribuições da escola dejouriana à análise da relação prazer, sofrimento e trabalho. São Paulo : Atlas.

Duraffourg, J. (2008). Santé au travail, santé du travail. Ergologia, (0), 155-176. Retirado de http:// www.ergologia.org/uploads/1/1/4/6/11469955/0_duraffourg.pdf

Durrive, L. (2007). O trabalho e o sujeito. In Y. Schwartz, \& L. Durrive (Org.), Trabalho e Ergologia, conversas sobre a atividade humana (pp. 295-307). Niterói : EDUFF.

Durrive, L., \& Schwartz, Y. (2008). Glossário da Ergologia. Laboreal, 4(1), 23-28. Retirado de http:// laboreal.up.pt/pt/articles/glossario-da-ergologia

Ferreira, J. (2010). O humanitário no Brasil : entre o ideal universal e a cultura local. In Ferreira, J., \& Schuch, P (Org.). Direitos e ajuda humanitária : perspectivas sobre família, gênero e saúde (pp. 25-48). Rio de Janeiro : Ed. Fiocruz.

Freitas, M. T., Souza, S. J., \& Kramer, S. (Org.). (2003). Ciências humanas e pesquisa : leituras de Mikhail Bakhtin. São Paulo : Cortez.

Lévinas, E. (1988). Le temps et L'Autre. Paris : Puf.

Nouroudine, A. (2004). Risco e atividades humanas : acerca da possível positividade aí presente. In M. Figueiredo, J. Brito, M. Athayde, \& D. Alvares, Labirintos do trabalho : interrogações e olhares sobre o trabalho vivo (pp. 37-62). Rio de Janeiro : DP\&A.

Pereira, R. A., \& Rodrigues, R. H. (2010). Os gêneros do discurso sob perspectiva da análise dialógica de discurso do círculo de Bakhtin. Letras, Santa Maria, 20(40), 147-162.

Pezé, M. (2009). Corps et souffrance au travail. Corps. Revue Interdisciplinaire, (6), 15-22.

Revuz, C. (2007). O trabalho e o sujeito. In Y. Schwartz, \& L. Durrive, L. (Orgs.), Trabalho e Ergologia, conversas sobre a atividade humana (pp. 226-246). Niterói : EDUFF. 
Rocha, D., Daher, M. D. C., \& Sant'anna, V. L. A. (2004). A entrevista em situação de pesquisa acadêmica : reflexões numa perspectiva discursiva. Polifonia, 1(8), 161-180. Retirado de http:// periodicoscientificos.ufmt.br/ojs/index.php/polifonia/article/view/1132/896

Schwartz, Y. (2003). O Trabalho em uma perspectiva filosófica [Comunicação apresentada em Seminário Educação e Trabalho : trabalhar, aprender, saber]. Cuiabá, MT : UFMT.

Schwartz, Y. (2004). Trabalho e gestão : níveis, critérios, instâncias. In M. Figueiredo, J. Brito, M. Athayde, \& D. Alvares, Labirintos do trabalho : interrogações e olhares sobre o trabalho vivo (pp. 23-33). Rio de Janeiro : DP\&A.

Schwartz, Y. (2005). Trabalho e saúde : construindo outros modos de gestão. Comunicação apresentada no Congresso da Abrasco, Florianópolis, Brasil.

Schwartz, Y. (2007a). O Trabalho se Modifica. In Y. Schwartz, \& L. Durrive (Orgs.), Trabalho e Ergologia, conversas sobre a atividade humana (pp. 25-36). Niterói : EDUFF.

Schwartz, Y. (2007b). Trabalho e Uso de Si. In Y. Schwartz, \& L. Durrive (Orgs.), Trabalho e Ergologia, conversas sobre a atividade humana (pp. 191-206). Niterói : EDUFF.

Schwartz, Y. (2007c). O Homem, o Mercado e a Cidade. In Y. Schwartz, \& L. Durrive (Orgs.). Trabalho e Ergologia, conversas sobre a atividade humana (pp. 249-275. Niterói : EDUFF.

Schwartz, Y., \& Echternacht, E. (2009). Le Corps-soi dans le milieu de tavail : comment se spécifie sa competence à vivre ? Corps : Revue Interdisciplinaire, (6), 31-38.

Schwartz, Y. (2011). Manifesto por um Ergoengajamento. In P. F. Bendassolli, \& L. A. Soboll (Orgs.), Clínicas do trabalho (pp. 132-166). São Paulo : Atlas.

Trinquet, P. (2010). Trabalho e educação : o método ergológico. Revista Histedbr, 10(38e), 93-113. doi :10.20396/rho.v10i38e.8639753

\section{RESUMOS}

O trabalho em saúde em situações extremas é o fio condutor desse artigo, que investiga a atividade de trabalhadores da ONG Médicos Sem Fronteiras, buscando compreender os usos de si, no confronto com a realidade do trabalho de cuidar, prestar socorro e salvar vidas. Os desafios impostos por contextos complexos tornam o trabalho mais exigente, expondo a vulnerabilidade de pacientes, trabalhadores e organizações, mas também sua capacidade de enfrentamento e superação. A perspectiva ergológica de Schwartz, a Psicodinâmica do Trabalho e a concepção de saúde de Canguilhem orientam a condução teórico-metodológico da pesquisa, de base qualitativa, que faz uso de entrevistas, além de visitas a Centros Operacionais de MSF. Os resultados encontrados revelam uma atividade instigante, onde há desejo, proteção institucional e valorização profissional ; mas, também, desgaste e pressão por uma vida "normal", conflitos de valores e relevância da cooperação para a preservação do sentido do trabalho no cuidado humanitário.

El trabajo en salud en situaciones extremas es el hilo conductor de este artículo, que investiga la actividad de trabajadores de la ONG Médicos Sin Fronteras, buscando comprender sus usos en la confrontación con la realidad del trabajo de cuidar, socorrer y salvar vidas. Los retos planteados por contextos complejos hacen el trabajo más exigente, exponiendo la vulnerabilidad de pacientes, trabajadores y organizaciones, pero también su capacidad de enfrentamiento y superación. La perspectiva ergológica de Schwartz, la Psicodinámica del Trabajo y la concepción de salud de Canguilhem proporcionan una orientación teórico-metodológica a la investigación, 
de base cualitativa, que recurre a entrevistas, además de visitas a Centros Operacionales de MSF. Los resultados revelan una actividad estimulante, donde hay deseo, protección institucional y reconocimiento profesional, pero también desgaste, presión por una vida "normal", conflictos de valores y relevancia de la cooperación para la preservación del sentido del trabajo en el cuidado humanitario.

Le fil conducteur de cet article est l'activité, en situations extrêmes, des travailleurs en santé de l'ONG Médecins Sans Frontières. On cherche à mieux comprendre les usages de soi en confrontation avec la réalité du travail de soigner, porter secours et sauver des vies. Les défis posés par des réalités complexes rendent le travail plus exigeant, mettant à épreuve la vulnérabilité des patients, des travailleurs, des organisations et leur capacité d'y surmonter. Les fondements théoriques et méthodologiques sont: la perspective ergologique de Schwartz, la Psychodynamique du Travail et le concept de santé tel que proposé par Canguilhem. Des visites et des entretiens menés au sein de centres opérationnels MSF ont nourri la recherche, menée dans une approche qualitative. Les résultats révèlent une activité vécue comme stimulante, où sont présents le désir, la protection institutionnelle et la valorisation professionnelle; mais également l'épuisement, la difficulté d'une vie " normale », le conflit de valeurs et l'importance de la coopération pour la sauvegarde du sens du travail dans la prestation de soins humanitaires

Healthcare work in extreme situations is the guiding principle of this paper, which investigates the activity of workers in the NGO Doctors Without Borders, seeking to understand the uses of self in the confrontation with the reality of healthcare work, help and lifesaving. The challenges posed by complex contexts make this work more demanding, exposing the vulnerability of patients, workers and organizations, but also their capacity to confront and overcome difficulties. Schwartz's ergological perspective, the Psychodynamics of Work and Canguilhem's conception of health provide the theoretical-methodological direction to the qualitative research that used interviews as well as visits to MSF Operational Centers. The results show a challenging activity, where there is desire, institutional protection and professional appreciation; but also strain and the pressure for a "normal" life ; conflicts of values, and the relevance of cooperation for the preservation of the sense of work in humanitarian care.

\section{ÍNDICE}

Palabras claves: cuidado en salud, trabajador de la salud, trabajo humanitario, ergología

Keywords: health care, health worker, humanitarian work, ergology

Mots-clés: soin, travailleur de la santé, travail humanitaire, ergologie

Palavras-chave: cuidado em saúde, trabalhador da saúde, trabalho humanitário, ergologia

\section{AUTORES}

\section{LUCIANA B. CAVANELLAS}

Fundação Oswaldo Cruz, Coordenação de Saúde do Trabalhador (CST/Cogepe/Fiocruz), Avenida Brasil, 4365. Pavilhão Carlos Augusto da Silva. Manguinhos, Rio de Janeiro, RJ, Brasil, 21040-36 ; luciana.cavanellas@fiocruz.br

\section{JUSSARA BRITO}

Fundação Oswaldo Cruz, Escola Nacional de Saúde Pública Sérgio Arouca (Ensp/Fiocruz) ; Rua Leopoldo Bulhões, 1480, Manguinhos, Rio de Janeiro, RJ, 21041-210 ; jussara@ensp.fiocruz.br 